STUDI

FRANCESI

\section{Studi Francesi}

Rivista quadrimestrale fondata da Franco Simone

171 (LVII | III) | 2013

FRANCO SIMONE E LA STORIOGRAFIA LETTERARIA -

Atti della giornata di studi nel centenario della nascita promossa dall'Accademia delle Scienze di Torino in collaborazione con «Studi Francesi» Torino - 24 maggio 2013

\title{
Yann Frémy, Verlaine: la parole ou l'oubli
}

\section{Mario Richter}

\section{(2) OpenEdition \\ 1 Journals}

\section{Edizione digitale}

URL: http://journals.openedition.org/studifrancesi/2840

DOI: $10.4000 /$ studifrancesi.2840

ISSN: 2421-5856

Editore

Rosenberg \& Sellier

\section{Edizione cartacea}

Data di pubblicazione: 1 dicembre 2013

Paginazione: 634

ISSN: 0039-2944

Notizia bibliografica digitale

Mario Richter, "Yann Frémy, Verlaine: la parole ou l'oubli », Studi Francesi [Online], 171 (LVII | III) | 2013,

online dal 30 novembre 2015, consultato il 18 septembre 2020. URL : http://journals.openedition.org/ studifrancesi/2840 ; DOI : https://doi.org/10.4000/studifrancesi.2840

Questo documento è stato generato automaticamente il 18 settembre 2020.

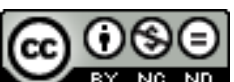

Studi Francesi è distribuita con Licenza Creative Commons Attribuzione - Non commerciale - Non opere derivate 4.0 Internazionale. 


\title{
Yann Frémy, Verlaine: la parole ou l'oubli
}

\author{
Mario Richter
}

\section{NOTIZIA}

YANN FRÉMY, Verlaine: la parole ou l'oubli, Paris, Academia L'Harmattan, 2012, pp. 187.

1 In questo agile libro Yann Frémy offre al lettore un suggestivo percorso attraverso alcuni fra i più significativi snodi dell'opera poetica di Verlaine, dai Poëmes saturniens alla Bonne chanson, dalle Romances sans paroles a Sagesse e Amour. Il suo modo di procedere costituisce indubbiamente una novità e consente di portare sul poeta, tanto ridimensionato e certo abbassato dai surrealisti, una luce nuova e di restituirgli un rilievo che il secolo scorso gli ha forse troppo ingiustamente negato, specialmente mettendolo a raffronto con Rimbaud.

2 Frémy interroga e commenta con attenzione tutte le testimonianze rimaste (iconografiche, letterarie e di qualunque altro genere) per riconsegnarci un'immagine a tutto tondo di Verlaine, un'immagine che appunto viene spesso a modificare una vulgata critica che poteva magari apparire definitiva. Si avvale costantemente di un'ampia informazione critica resa attiva e necessaria dalla sua stringente argomentazione, tale comunque da esimerlo dal fornire una bibliografia che, praticata secondo i consueti criteri, spesso risulta incongrua o pleonastica.

3 Frémy intende dimostrare che Verlaine, pur conoscendo l'ininterrotta e devastante insidia dell'assenza e della malinconia (defezione provvisoria di Mathilde, scomparsa di Rimbaud e di Lucien Létinois che implica, con l'orrore della morte, una conversione religiosa carica di ambiguità), non perde mai il completo possesso dei suoi mezzi intellettuali e poetici, capaci di contrastare vittoriosamente la dimenticanza (appunto l' oubli presente nel titolo) che in ogni momento lo insidia con l'intensità di un'ossessione infernale. È così messa in chiara luce la straordinaria energia che immancabilmente conferisce all'opera di Verlaine un significato pregnante e una vigorosa tenuta estetica. 
A questo proposito, fra le numerose e puntuali incursioni critiche in singoli aspetti del mondo verlainiano, suscitano un particolare interesse le osservazioni e le sottili analisi del critico sulle Notes de nuit, delle quali egli riproduce utilmente il testo originario della «Revue indépendante» (novembre 1884) e non quello, normalmente proposto, fornito da Delahaye nel 1919. Tutto il libro è del resto illuminato da considerazioni fini e intelligenti, sostenute da una solida dottrina, tali comunque che consentono di rileggere Verlaine in una prospettiva nuova, specie per quanto riguarda la problematica religione del poeta, che di fatto risulta dominata dalla poesia (la quale «reprend au christianisme son bien», dice l'A. a p. 160) ed è opportunamente rivisitata secondo la "duplicité" già rilevata da Solenn DUPAs in un articolo che l'A. giustamente segnala e che è stato pubblicato qualche anno fa in questa rivista (cfr. Poétiques de l'intime dans "Amour", n. 154, gennaio-aprile 2008). 